Curr Opin Psychiatry. 2007 May ; 20(3): 268-272. doi:10.1097/YCO.0b013e3280ba4975.

\title{
Cognitive heterogeneity in schizophrenia
}

\author{
Eileen M. Joyce and Jonathan P. Roiser \\ UCL Institute of Neurology, London, UK
}

\begin{abstract}
Purpose-Further clarification of the nature of cognitive heterogeneity in schizophrenia is needed to aid the endophenotype approach to the understanding of the genetic basis of the disorder. This review summarizes recent neuropsychological studies of schizophrenia, aimed at establishing whether there are valid forms of cognitive impairment that can be defined with the use of neuropsychological measures in patients with schizophrenia, and studies that have attempted to relate specific neuropsychological findings to genetic polymorphisms.
\end{abstract}

Recent findings-There is good evidence for significant cognitive heterogeneity in schizophrenia. It is not yet clear, however, whether this heterogeneity is better accounted for by a general loss of function, varying in degree between different patients, or by impairment in specific cognitive abilities, for example working memory. Molecular genetic studies have provided evidence for associations of single nucleotide polymorphisms with both specific and general impairments, with some additional support for a working memory deficit from neuroimaging studies.

Summary-Larger, better controlled studies are needed before the genetic sources of cognitive heterogeneity in schizophrenia can be accurately characterized. This will be aided with the development and use of more specific neuropsychological tasks that can accurately discriminate between different cognitive domains.

\section{Keywords}

cognition; IQ; polymorphisms; schizophrenia; working memory

\section{Introduction}

Brain imaging and neuropathological studies have shown that the neural disturbance in schizophrenia involves cortical and subcortical areas, thought to mediate a number of discrete cognitive operations. A recent review [1] has confirmed that several 'domains' of cognitive impairment are reliably found in neuropsychological studies. The question arises as to whether these domain-specific impairments are ubiquitous, varying from person to person in severity, or whether certain domains are more prevalent in subgroups of patients. Further clarification of the nature of cognitive heterogeneity in schizophrenia is needed to aid the endophenotype approach to the understanding of the genetic basis of the disorder $[2,3]$. This approach proposes that strictly defined neurobiological features of schizophrenia are likely to be a more direct expression of genetic polymorphisms affecting neural structure and function than are clinical manifestations. Endophenotypes such as certain electrophysiological responses or neuroimaging abnormalities are likely to be fruitful in this

(C) 2007 Lippincott Williams \& Wilkins.

Correspondence to Professor E.M. Joyce, UCL Institute of Neurology, Box 19, The National Hospital for Neurology and Neurosurgery, Queen Square, London WC1N 3BG, UK, Tel: +44 207837 3611; e-mail: e.joyce@ion.ucl.ac.uk. 
regard [4] but it is difficult to perform these laboratory-based studies in the numbers required for genetic studies. Neuropsychological tests on the other hand can be performed in large numbers in clinical settings. Therefore, it is important to establish whether there are valid forms of cognitive impairment that can be defined with the use of neuropsychological measures. This review summarizes the recent neuropsychological studies of schizophrenia aimed at defining the neuropsychological deficit more closely, and studies that have attempted to relate neuropsychological findings to genetic variation.

\section{Neuropsychological impairment is a core feature of schizophrenia}

Previous studies [5-8] have found that 20-30\% of patients perform within the normal range across different neuropsychological tests. Other studies [9-13] conclude that schizophrenia patients performing in the normal range show evidence of decline from higher premorbid levels of ability and/or more specific cognitive impairments. Wilk et al. [14] examined this question by matching patients individually with healthy controls for age, years of education and current full scale intelligence quotient (IQ). The profile of the two groups differed on the index measures of the Wechsler Adult Intelligence Scale III, in that patients performed better than controls on verbal comprehension and perceptual organization but worse on processing speed and working memory. A discrepancy between the immediate and general memory index scores of the Wechsler Memory Scale III and full scale IQ was present in patients but not in controls, implying a disproportionate memory impairment. When the authors restricted the analysis to high IQ subjects, they found a similar index profile with immediate memory being particularly impaired in patients. The authors concluded that the patients had declined from a higher level of function, as verbal comprehension is resistant to change, and that this was evident for processing speed and memory. A study of first episode patients [15] matched high-normal current IQ patients with healthy controls for age, current IQ and estimated premorbid IQ. Patients were no different from controls on a number of measures but were still impaired on a measure of working memory. These findings give further support to the view that cognitive impairment is a fundamental feature of schizophrenia, even in those patients with seemingly intact intellectual function.

\section{Specific cognitive subtypes in schizophrenia}

Studies $[14,15]$ suggest that there are groups at all illness stages with specifically impaired executive function and/or memory. The concept of cognitive subgroups is not new: two centres have reliably found cognitive subgroups using cluster analysis [5,6,16-18]. The two most consistently identified are of generalized impairment and of normal performance, except executive function. When test cut-off scores were used in first episode and established schizophrenia studies, three cognitive subgroups emerged: IQ decline from higher premorbid values; low premorbid IQ; and specific executive dysfunction [15,19].

None of the above studies elucidated a specific memory subgroup. Other studies have suggested separable Huntington's disease-like and Alzheimer's disease-like profiles in schizophrenia $[20,21]$. On the other hand, a recent study [22 $]$, which examined this issue in more detail using different methods to analyse the same data, failed to support the presence of complex dementia-like memory subgroups. Rather, patients could be more simply dichotomized into memory impaired and unimpaired groups, neither of which differed on measures of IQ or executive function, thus supporting previous findings $\left[9,22^{\circ}\right]$.

\section{Stability of cognitive subtypes in schizophrenia}

If there are three valid cognitive subtypes of schizophrenia—namely, generalized impairment/decline, executive dysfunction and memory dysfunction - then they should be stable over time. Unfortunately, there are few longitudinal studies [18]. The memory study 
described above $\left[22^{\circ}\right]$ examined the stability of memory subgroups by testing patients 3 years later. They found only moderate stability, with nearly $20 \%$ of patients changing classification. The need for more studies characterizing patients over time was emphasized by another recent study of schizophrenia which compared estimated premorbid IQ with current IQ measured at the first episode and 10 years later [23]. Evidence of cognitive decline at onset was found but 10 years later this was no longer evident as current IQ was then no different from premorbid estimates. Thus cognitive subtypes defined at the first episode (e.g., see Joyce et al. [15]) require confirmation by longitudinal assessments if they are to be accepted as trait markers of schizophrenia.

\section{Problems with the concept of independent cognitive domains in schizophrenia}

The review by Nuechterlein et al. [1] began by suggesting that discrete domains of cognitive impairment are reliably found in schizophrenia. Although this is not evidence for cognitive subtypes per se, this study concluded that the domains identified are largely independent and that variations in cognitive function among patients and between patients and healthy individuals might be understood from this perspective. The view that differences between schizophrenia patients and healthy individuals may be due to specific, identifiable cognitive processes has been challenged [24,25*]. One study [24], by submitting subtest variables from the Wechsler Adult Intelligence Scale III and Wechsler Memory Scale III to single common factor analysis, showed that two thirds of the difference in cognitive performance between schizophrenia and healthy control groups was mediated by a common cognitive factor. Thus performance on subtests co-varied, with performance on one subtest predicting performance on the remainder. In another study $\left[25^{\circ}\right.$ ], the same group showed that within both schizophrenia and healthy control groups, a large amount of the variance in neuropsychological performance could be attributed to a single general ability factor. Using confirmatory factor analysis, they found that the results of patients with schizophrenia fitted a hierarchical model in which a large number of neuropsychological test results could be reduced to a smaller number of cognitive domains and, in turn, these domains 'loaded' on a single factor corresponding to general cognitive ability. This hierarchical model is well known to fit data from healthy populations but the difference between the healthy controls and patients in this study was that the schizophrenia group appeared to rely more heavily on general cognitive ability than on individual cognitive processes. Two explanations for this finding were provided $\left[25^{\circ}\right]$. One was that conventional neuropsychological tests are so confounded, in that each 'specific' test actually relies on a number of diverse cognitive processes for performance, that they cannot be used to discriminate among various cognitive processes. The other was that the abnormal neurobiological substrate accounting for the cognitive impairment in schizophrenia is diffuse.

\section{Cognitive heterogeneity and the search for the genetic basis of schizophrenia}

The conflicting evidence of whether there are discrete, differentially affected cognitive domains in schizophrenia is mirrored by conflicting evidence from studies that have looked for relationships between particular single nucleotide polymorphisms (SNPs) and cognitive dysfunction. These studies are beset with other problems including small sample sizes, heterogeneous ethnic origin, and deviations from Hardy-Weinberg equilibrium assumptions. Thus the evidence for the association of cognitive impairment in schizophrenia with specific SNPs is variable. Nevertheless, the published studies from the past few years provide promising, if not unequivocal, evidence that variation in particular genes known to affect 
neural development and function might explain at least some of the heterogeneity observed in cognitive performance in patients with schizophrenia.

\section{Dysbindin and cathecol-o-methyltransferase}

The majority of recent studies investigating associations between genetic variation and cognitive performance have examined SNPs in either dysbindin or cathecol-omethyltransferase (COMT) genes. In general, the strategy followed in these studies is to test schizophrenia patients on several cognitive measures, genotype the patients for specific SNPs and look for associations of alleles with either general or specific cognitive measures. One study, however, stands out for having used a more principled endophenotype approach. Hallmayer et al. [26], building on previous work [27], dichotomized schizophrenia patients into 'cognitively spared' and 'cognitive deficit' groups using neuropsychological tests and latent variable analysis, thus defining the endophenotype of interest prior to genotyping. They then performed a genome-wide scan comparing the two patient groups, and found an association of 'cognitive deficit' schizophrenia (i.e., a general impairment) with a marker on chromosome 6 that had previously been associated with schizophrenia in an independent sample [28], close to the dysbindin gene.

Two other recent studies have examined the effect of SNPs or haplotypes in the dysbindin gene on cognitive performance in schizophrenia [29,30]. One of these also reported associations with general impairment (estimated IQ decline [30]) while the other reported an association with spatial working memory performance in the absence of relationships with other measures, including premorbid IQ [29]. In the latter study, dysbindin haplotype explained $12 \%$ of the variation in working memory performance, a much larger effect than is commonly reported in studies of this type. Unfortunately, these two studies reported the effects of different SNPs/haplotypes, and so are not directly comparable. Nevertheless, it is notable that the three studies implicating this locus found an association with one or other of the most regularly identified cognitive subtypes: generalized cognitive impairment/decline and specific executive impairment.

A similar spectrum of findings pertains to COMT, an enzyme involved in the metabolism of dopamine (DA). Most studies investigating cognitive performance have focused on the $v^{1}{ }^{108 / 158}$ met polymorphism. Since the initial report of better executive performance on the Wisconsin Card Sort Test (WCST) in patients carrying the met allele [31], which results in impaired enzyme function and therefore increased DA availability in the prefrontal cortex (PFC), several studies have investigated the association of the val ${ }^{108 / 158}$ met polymorphism with cognitive performance in patients with schizophrenia. While some of these studies provided confirmatory evidence that the val allele is associated with impaired performance on tests of working memory [29,32] and attention [33] (in the absence of effects on general cognitive ability), another suggested an association of the val allele with general cognitive decline [34]. Others have been unable to replicate these findings [35-39], or found differential effects of the SNP on performance of the Wisconsin Card Sort Test in males and females [40]. Interestingly, the most consistent finding in this field is that patients carrying the met/met genotype show improved executive function following the initiation of treatment with atypical antipsychotics [32,41,42].

One unanswered question about these findings is how specific the effects are to schizophrenia. The studies that contained control groups often found the same effect of val $^{108 / 158}$ met polymorphism on cognitive performance in controls as well as in patients [31,40]. In addition, based on an inverted U model of DA modulation of working memory performance [43], D2 blockade would be predicted to have the most beneficial effects in met/met individuals, even in healthy volunteers. In summary, many studies of the COMT 
val ${ }^{108 / 158}$ met polymorphism indicate associations with impairments in specific cognitive functions, in particular those dependent on the dorsolateral PFC, such as working memory and attention. The consistency and specificity of the findings, however, remain unclear.

\section{Other polymorphisms}

A number of studies have investigated associations between other SNPs and cognitive function in schizophrenia. About half of these studies report associations with specific measures of working memory or attention, and half with general cognitive function. For example, Rybakowski et al. [44] reported that the met allele at the val ${ }^{66}$ met polymorphism in the brain derived neurotrophic factor (BDNF) gene was associated with impaired working memory performance, an effect that was not seen in patients with bipolar disorder. The distribution of genotypes in the schizophrenia group, however, differed significantly from the Hardy-Weinberg equilibrium in this sample. Nevertheless, consistent with this finding, Ho et al. [45] reported that, while the met allele was associated with impaired verbal memory in both patients and controls, the met allele was associated with a visuospatial processing impairment only in patients with schizophrenia.

Burdick et al. [46] reported an association between a polymorphism in the DISC-1 gene and impaired working memory performance in African-American, but not Caucasian, patients, although the effect of the genotype on working memory performance in Caucasian patients was in the same direction as in the African-American patients. Goldberg et al. [47] investigated the association of a number of SNPs within the G72 (also known as DAOA) gene with cognitive function in a large sample of patients with schizophrenia and in controls. They reported a genotype-by-diagnosis interaction at two loci; both SNPs were associated with working memory impairment solely in the patient group, with no effect in the controls. Notably, both of these studies reported an association of alleles previously suggested to confer risk of schizophrenia with impaired working memory performance in the patient group.

\section{Neuroanatomical and neurophysiological studies}

Building on advances in our understanding of the neural basis of specific cognitive functions (e.g., that working memory performance is critically dependent on intact dorsolateral PFC function), a number of recent studies have attempted to provide a greater understanding of how genetic variation might result in cognitive heterogeneity in schizophrenia using neuroanatomical and neurophysiological techniques, such as MRI and PET. Nevertheless, it is important to note a number of caveats: no two studies have yet reported the same result; neuroimaging studies are vulnerable to false positives if appropriate statistical correction is not applied; many studies use small sample sizes; and there is likely to be a publication bias against negative findings in this field.

Some structural MRI studies have reported associations of SNPs with grey matter volume reduction in the frontal lobe (although not always the same area of the frontal lobe), including brain derived neurotrophic factor [45,48], COMT [38] and a novel locus on chromosome 8 [49]. Another study could not replicate the finding that the met allele at the COMT val ${ }^{108 / 158}$ met polymorphism was associated with grey matter reduction in the PFC but did report that met homozygous schizophrenia patients showed improved PFC efficiency during working memory performance compared with val homozygous patients, as measured with PET [37]. This finding is consistent with an earlier functional MRI study [41] which reported that antipsychotic medication improved both working memory function and PFC efficiency during working memory performance in met homozygous patients but not in val carriers. 


\section{Conclusion}

In summary, there is good evidence for significant cognitive heterogeneity in schizophrenia. It is not yet clear, however, whether this heterogeneity is better accounted for by a general loss of function, varying in degree between different patients, or impairment in specific cognitive abilities (e.g., working memory). Molecular genetic studies have provided evidence for associations of SNPs with both specific and general impairments, with some additional support for a working memory deficit from neuroimaging studies. Failures to replicate are unfortunately the norm, rather than the exception, in this field. This may be partly because of an inherent problem with some of the neuropsychological tasks being used in an attempt to identify specific forms of impairment. Larger, better controlled studies are therefore needed before the sources of cognitive heterogeneity in schizophrenia can be accurately characterized, and this will be aided by the use of more specific neuropsychological tests.

\section{Abbreviations}

COMT cathecol-o-methyltransferase

PFC prefrontal cortex

SNP single nucleotide polymorphism

\section{References and recommended reading}

Papers of particular interest, published within the annual period of review, have been highlighted as:

- of special interest

•• of outstanding interest

Additional references related to this topic can also be found in the Current World Literature section in this issue (p. 307).

1. Nuechterlein KH, Barch DM, Gold JM, et al. Identification of separable cognitive factors in schizophrenia. Schizophr Res. 2004; 72:29-39. [PubMed: 15531405]

2. Gottesman II, Gould TD. The endophenotype concept in psychiatry: etymology and strategic intentions. Am J Psychiatry. 2003; 160:636-645. [PubMed: 12668349]

3. Braff DL, Freedman R, Schork NJ, Gottesman II. Deconstructing schizophrenia: an overview of the use of endophenotypes in order to understand a complex disorder. Schizophr Bull. 2007; 33:21-32. [PubMed: 17088422]

4. Stephan KE, Baldeweg T, Friston KJ. Synaptic plasticity and dysconnection in schizophrenia. Biol Psychiatry. 2006; 59:929-939. [PubMed: 16427028]

5. Goldstein G. Neuropsychological heterogeneity in schizophrenia: a consideration of abstraction and problem-solving abilities. Arch Clin Neuropsychol. 1990; 5:251-264. [PubMed: 14589685]

6. Heinrichs RW, Awad AG. Neurocognitive subtypes of chronic schizophrenia. Schizophr Res. 1993; 9:49-58. [PubMed: 8096391]

7. Palmer BW, Heaton RK, Paulsen JS, et al. Is it possible to be schizophrenic yet neuropsychologically normal? Neuropsychology. 1997; 11:437-446. [PubMed: 9223148]

8. Holthausen EA, Wiersma D, Sitskoorn MM, et al. Schizophrenic patients without neuropsychological deficits: subgroup, disease severity or cognitive compensation? Psychiatry Res. 2002; 112:1-11. [PubMed: 12379446]

9. Kremen WS, Seidman LJ, Faraone SV, et al. The paradox of normal neuropsychological function in schizophrenia. J Abnorm Psychol. 2000; 109:743-752. [PubMed: 11196000] 
10. Kremen WS, Seidman LJ, Faraone SV, et al. Heterogeneity of schizophrenia: a study of individual neuropsychological profiles. Schizophr Res. 2004; 71:307-321. [PubMed: 15474901]

11. Kremen WS, Seidman LJ, Faraone SV, Tsuang MT. Intelligence quotient and neuropsychological profiles in patients with schizophrenia and in normal volunteers. Biol Psychiatry. 2001; 50:453462. [PubMed: 11566163]

12. Allen DN, Goldstein G, Warnick E. A consideration of neuropsychologically normal schizophrenia. J Int Neuropsychol Soc. 2003; 9:56-63. [PubMed: 12570358]

13. Horan WP, Goldstein G. A retrospective study of premorbid ability and aging differences in cognitive clusters of schizophrenia. Psychiatry Res. 2003; 118:209-221. [PubMed: 12834815]

14. Wilk CM, Gold JM, McMahon RP, et al. No, it is not possible to be schizophrenic yet neuropsychologically normal. Neuropsychology. 2005; 19:778-786. [PubMed: 16351353]

15. Joyce EM, Hutton SB, Mutsatsa SH, Barnes TR. Cognitive heterogeneity in first-episode schizophrenia. Br J Psychiatry. 2005; 187:516-522. [PubMed: 16319403]

16. Goldstein G, Allen DN, Seaton BE. A comparison of clustering solutions for cognitive heterogeneity in schizophrenia. J Int Neuropsychol Soc. 1998; 4:353-362. [PubMed: 9656609]

17. Goldstein G, Shemansky WJ. Influences on cognitive heterogeneity in schizophrenia. Schizophr Res. 1995; 18:59-69. [PubMed: 8929762]

18. Heinrichs RW, Ruttan L, Zakzanis KK, Case D. Parsing schizophrenia with neurocognitive tests: evidence of stability and validity. Brain Cogn. 1997; 35:207-224. [PubMed: 9356162]

19. Weickert TW, Goldberg TE, Gold JM, et al. Cognitive impairments in patients with schizophrenia displaying preserved and compromised intellect. Arch Gen Psychiatry. 2000; 57:907-913. [PubMed: 10986554]

20. Paulsen JS, Heaton RK, Sadek JR, et al. The nature of learning and memory impairments in schizophrenia. J Int Neuropsychol Soc. 1995; 1:88-99. [PubMed: 9375213]

21. Turetsky BI, Moberg PJ, Mozley LH, et al. Memory-delineated subtypes of schizophrenia: relationship to clinical, neuroanatomical, and neurophysiological measures. Neuropsychology. 2002; 16:481-490. [PubMed: 12382987]

22. Vaz SM, Heinrichs RW. Stability and validity of memory-based subtypes of schizophrenia. J Int Neuropsychol Soc. 2006; 12:782-791. [PubMed: 17064442]

- This study fully explores the typology of memory deficits in schizophrenia and suggests that a more simple classification (impaired/unimpaired) fitted the data best. It showed that even this classification had only moderate stability over time, however.

23. van Winkel R, Myin-Germeys I, Delespaul P, et al. Premorbid IQ as a predictor for the course of IQ in first onset patients with schizophrenia: A 10-year follow-up study. Schizophr Res. 2006; 88:47-54. [PubMed: 16904292]

24. Dickinson D, Iannone VN, Wilk CM, Gold JM. General and specific cognitive deficits in schizophrenia. Biol Psychiatry. 2004; 55:826-833. [PubMed: 15050864]

25. Dickinson D, Ragland JD, Calkins ME, et al. A comparison of cognitive structure in schizophrenia patients and healthy controls using confirmatory factor analysis. Schizophr Res. 2006; 85:20-29. [PubMed: 16616831]

••. This study grapples with the concept of specific cognitive impairments in schizophrenia with the use of sophisticated statistical analysis of multiple neuropsychological variables in schizophrenia and healthy controls. Both groups showed the same hierarchical structure whereby performance in different cognitive domains can be substantially explained by a single general ability factor.

26. Hallmayer JF, Kalaydjieva L, Badcock J, et al. Genetic evidence for a distinct subtype of schizophrenia characterized by pervasive cognitive deficit. Am J Hum Genet. 2005; 77:468-476. [PubMed: 16080121]

27. Hallmayer JF, Jablensky A, Michie P, et al. Linkage analysis of candidate regions using a composite neurocognitive phenotype correlated with schizophrenia. Mol Psychiatry. 2003; 8:511523. [PubMed: 12808431]

28. Straub RE, MacLean CJ, Ma Y, et al. Genome-wide scans of three independent sets of 90 Irish multiplex schizophrenia families and follow-up of selected regions in all families provides evidence for multiple susceptibility genes. Mol Psychiatry. 2002; 7:542-559. [PubMed: 12140777] 
29. Donohoe G, Morris DW, Clarke S, et al. Variance in neurocognitive performance is associated with dysbindin-1 in schizophrenia: A preliminary study. Neuropsychologia. 2007; 45:454-458. [PubMed: 16930638]

30. Burdick KE, Goldberg TE, Funke B, et al. DTNBP1 genotype influences cognitive decline in schizophrenia. Schizophr Res. 2007; 89:169-172. [PubMed: 17074466]

31. Egan MF, Goldberg TE, Kolachana BS, et al. Effect of COMT Val108/158 Met genotype on frontal lobe function and risk for schizophrenia. Proc Natl Acad Sci USA. 2001; 98:6917-6922. [PubMed: 11381111]

32. Woodward ND, Jayathilake K, Meltzer HY. COMT val108/158met genotype, cognitive function, and cognitive improvement with clozapine in schizophrenia. Schizophr Res. Nov 21.2006 Epub ahead of print.

33. Bilder RM, Volavka J, Czobor P, et al. Neurocognitive correlates of the COMT Val(158)Met polymorphism in chronic schizophrenia. Biol Psychiatry. 2002; 52:701-707. [PubMed: 12372660]

34. Mata I, Arranz MJ, Staddon S, et al. The high-activity Val allele of the catechol-Omethyltransferase gene predicts greater cognitive deterioration in patients with psychosis. Psychiatr Genet. 2006; 16:213-216. [PubMed: 16969277]

35. Golimbet V, Gritsenko I, Alfimova M, et al. Association study of COMT gene Val158Met polymorphism with auditory $\mathrm{P} 300$ and performance on neurocognitive tests in patients with schizophrenia and their relatives. World J Biol Psychiatry. 2006; 7:238-245. [PubMed: 17071544]

36. Szoke A, Schurhoff F, Meary A, et al. Lack of influence of COMT and NET genes variants on executive functions in schizophrenic and bipolar patients, their first-degree relatives and controls. Am J Med Genet B Neuropsychiatr Genet. 2006; 141:504-512. [PubMed: 16741933]

37. Ho BC, Wassink TH, O'Leary DS, et al. Catechol-O-methyl transferase Val158Met gene polymorphism in schizophrenia: working memory, frontal lobe MRI morphology and frontal cerebral blood flow. Mol Psychiatry. 2005; 10:229, 287-298. [PubMed: 15668720]

38. Ohnishi T, Hashimoto R, Mori T, et al. The association between the Val158Met polymorphism of the catechol-O-methyl transferase gene and morphological abnormalities of the brain in chronic schizophrenia. Brain. 2006; 129(Pt 2):399-410. [PubMed: 16330500]

39. Rosa A, Peralta V, Cuesta MJ, et al. New evidence of association between COMT gene and prefrontal neurocognitive function in healthy individuals from sibling pairs discordant for psychosis. Am J Psychiatry. 2004; 161:1110-1112. [PubMed: 15169701]

40. Rybakowski JK, Borkowska A, Czerski PM, et al. Performance on the Wisconsin Card Sorting Test in schizophrenia and genes of dopaminergic inactivation (COMT, DAT, NET). Psychiatry Res. 2006; 143:13-19. [PubMed: 16712949]

41. Bertolino A, Caforio G, Blasi G, et al. Interaction of COMT (Val(108/158)Met) genotype and olanzapine treatment on prefrontal cortical function in patients with schizophrenia. Am J Psychiatry. 2004; 161:1798-1805. [PubMed: 15465976]

42. Weickert TW, Goldberg TE, Mishara A, et al. Catechol-O-methyltransferase val108/158met genotype predicts working memory response to antipsychotic medications. Biol Psychiatry. 2004; 56:677-682. [PubMed: 15522252]

43. Mattay VS, Goldberg TE, Fera F, et al. CatecholO-methyltransferase val158-met genotype and individual variation in the brain response to amphetamine. Proc Natl Acad Sci U S A. 2003; 100:6186-6191. [PubMed: 12716966]

44. Rybakowski JK, Borkowska A, Skibinska M, et al. Prefrontal cognition in schizophrenia and bipolar illness in relation to Val66Met polymorphism of the brain-derived neurotrophic factor gene. Psychiatry Clin Neurosci. 2006; 60:70-76. [PubMed: 16472361]

45. Ho BC, Milev P, O'Leary DS, et al. Cognitive and magnetic resonance imaging brain morphometric correlates of brain-derived neurotrophic factor Val66Met gene polymorphism in patients with schizophrenia and healthy volunteers. Arch Gen Psychiatry. 2006; 63:731-740. [PubMed: 16818862]

46. Burdick KE, Hodgkinson CA, Szeszko PR, et al. DISC1 and neurocognitive function in schizophrenia. Neuroreport. 2005; 16:1399-1402. [PubMed: 16056147] 
47. Goldberg TE, Straub RE, Callicott JH, et al. The G72/G30 gene complex and cognitive abnormalities in schizophrenia. Neuropsychopharmacology. 2006; 31:2022-2032. [PubMed: 16554747]

48. Agartz I, Sedvall GC, Terenius L, et al. BDNF gene variants and brain morphology in schizophrenia. Am J Med Genet B Neuropsychiatr Genet. 2006; 141:513-523. [PubMed: 16741916]

49. Gurling HM, Critchley H, Datta SR, et al. Genetic association and brain morphology studies and the chromosome 8p22 pericentriolar material 1 (PCM1) gene in susceptibility to schizophrenia. Arch Gen Psychiatry. 2006; 63:844-854. [PubMed: 16894060] 